\title{
Cardiovascular risk management in patients with inflammatory arthritis: what is good for the joint is good for the heart and vice versa!
}

\author{
Ulf Müller-Ladner ${ }^{1,2}$, Ingo H Tarner ${ }^{1,2}$, Christian Hamm ${ }^{3}$ and Uwe Lange ${ }^{2}$
}

\author{
Addresses: ${ }^{1}$ Department of Internal Medicine and Rheumatology, Justus-Liebig University Giessen, Giessen, Germany; ${ }^{2}$ Department of \\ Rheumatology and Clinical Immunology, Kerckhoff Clinic Bad Nauheim, Benekestrasse 2-8, 61231 Bad Nauheim, Germany; \\ ${ }^{3}$ Department of Cardiology, Kerckhoff Clinic Bad Nauheim, Benekestrasse 2-8, 61231 Bad Nauheim, Germany \\ *Corresponding author: Ulf Müller-Ladner (u.mueller-ladner@kerckhoff-klinik.de) \\ FI000 Medicine Reports 2010, 2:27 (doi:10.3410/M2-27)
}

The electronic version of this article is the complete one and can be found at: http://fl000.com/reports/medicine/content/2/27

\begin{abstract}
Owing to the prominent long-term systemic inflammatory reaction in patients with arthritides and a growing body of data illustrating that this inflammatory reaction imposes a considerable risk for the development or aggravation of cardiovascular (CV) disease or overall CV risk, numerous researchers and clinicians have put enormous effort into the analysis of the effects of risk factors on the course of $\mathrm{CV}$ disease in these patients and the therapeutic options to antagonize progressive atherosclerosis. To achieve this challenging goal, investigators have shown that all treatment strategies must include the 'non-rheumatic' approaches, such as lowering blood pressure, stopping smoking, and improving metabolic status, in tight association with lowering the overall disease activity of the underlying rheumatic entity using antiphlogistic drugs and conventional as well as biologic disease-modifying drugs.
\end{abstract}

\section{Introduction and context}

The pathophysiology of all arthritides includes articular inflammation. In the majority of patients, this is associated with a continuous vascular flow of proinflammatory molecules that are also operative in the development of vascular lesions that may lead to atherosclerosis, resulting in a long-term systemic inflammatory reaction, and a growing body of data illustrates that this inflammatory reaction imposes a considerable risk for the development or aggravation of cardiovascular (CV) morbidity, which persists independently of the 'traditional' risk factors of endothelial dysfunction and atherosclerosis (as long as the underlying rheumatic disease is not in remission). A recent systematic review and meta-analysis of CV mortality in more than 90,000 patients with rheumatoid arthritis (RA) over the course of 50 years in the pre-biologics era revealed that the overall pooled standard mortality ratio (SMR) was calculated as 1.6 and did not change significantly over time [1]. This observation does not appear to inherit a regional effect - at least for Europe - as a similar approach asking the same questions to Swedish patients [2] also revealed no difference in SMR in the 1978 and 1995 cohorts, although, as noted by the authors, RA treatment had significantly improved for the later cohort. In addition, it needs to be noted that, in the CARRE (CARdiovascular research and RhEumatoid arthritis) investigation, about one-third of the $\mathrm{CV}$ events occurred prior to the onset of RA and this risk was comparable to diabetes type 2 patients $[3,4]$.

Basic science data from both cardiology and rheumatology have facilitated detailed molecular insight into the processes leading to atherosclerosis based on chronic inflammatory processes. As illustrated in Figure 1, inflammatory joint diseases and connective tissue diseases share several of these pathways, including all cellular components of the vascular and perivascular compartments [5]. In RA, basically all components of its pathophysiology, such as proinflammatory cytokines, 
Figure I. Pathophysiologic processes in inflammatory diseases leading to atherosclerotic lesions [5]

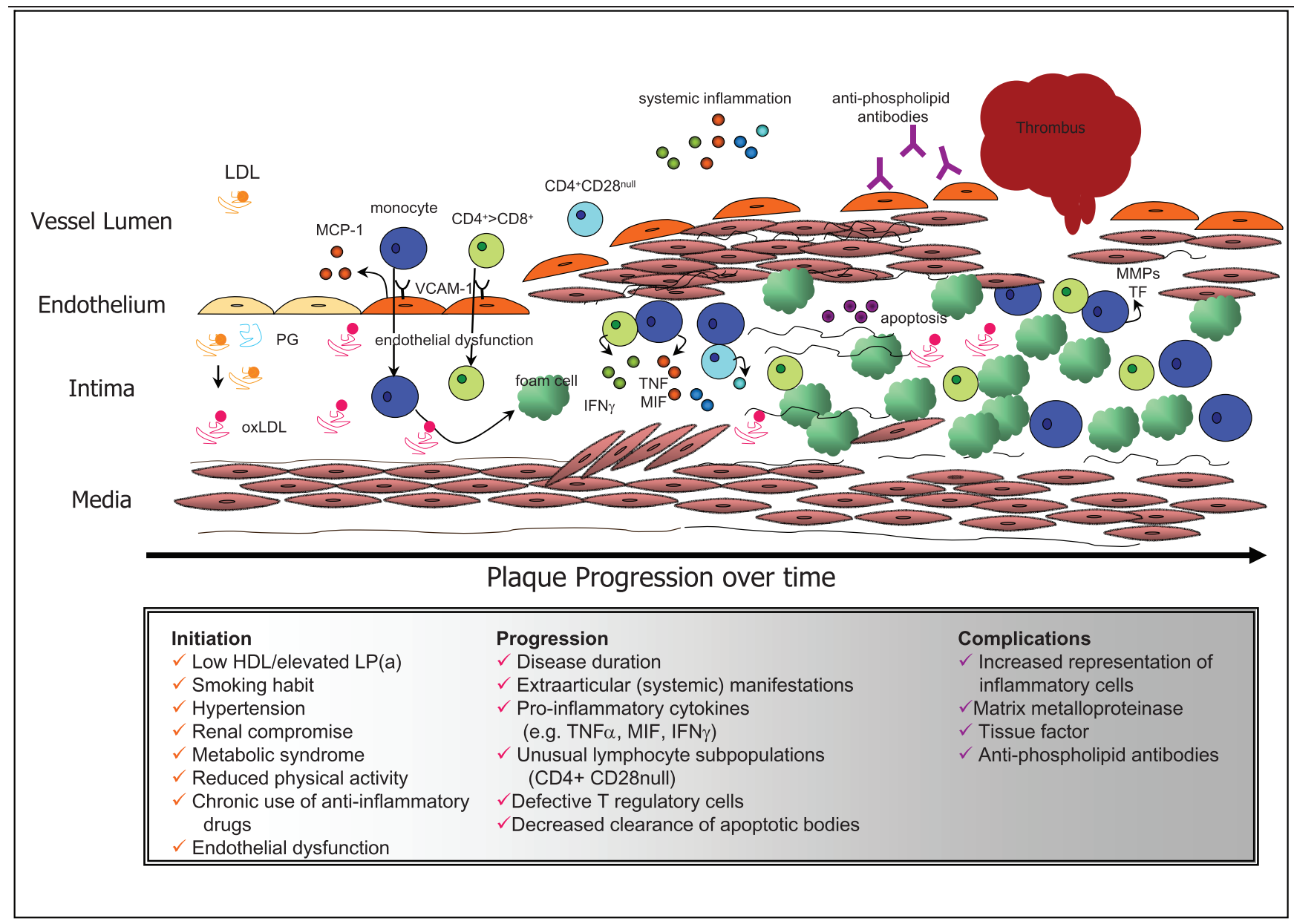

The initiation phase is driven by various stimuli, which are frequently based on metabolic dysfunctions and vasculotoxic lifestyle habits. As soon as vascular lesions are present, several proinflammatory molecules such as cytokines and immune cells contribute to the perpetuation of the progression of the inflammatory plaque. Finally, this concert of vasculoremodeling factors results in severe reduction in blood flow and development of thrombotic events. HDL, high-density lipoprotein; IFN $\gamma$, interferon-gamma; LDL, low-density lipoprotein; LP(a), lipoprotein (a); MCP-I, monocyte chemoattractant protein-I; MIF, migration inhibitory factor; MMP, matrix metalloproteinase; oxLDL, oxidized low-density lipoprotein; PG, prostaglandin; TF, tissue factor; TNF, tumor necrosis factor; VCAM-I, vascular cell adhesion molecule-I.

Reproduced from Full et al., 2009 [5]. Copyright @ 2009 BioMed Central Ltd.

altered perivascular metabolism, effector cells of the immune system, and circulating autoantibodies, mediate and promote an accelerated development of atherosclerotic lesions in the vascular wall (Figure 2) [6].

Therefore, as outlined below, inflammatory arthritides such as RA should be considered an additional independent risk factor for $\mathrm{CV}$ disease and these patients need to be treated more actively for CV prevention and risk factor modification, not unlike, for example, patients with metabolic diseases associated with a high CV risk. This treatment strategy certainly must include the 'nonrheumatic' standard measures such as lowering blood pressure (BP), cessation of smoking, and so on. Furthermore, it has been found that some 'cardiologic' drugs have both vasculoprotective and anti-inflammatory effects. For example, statins were shown to improve endothelial function [7] as well as reduce arterial stiffness, lipid oxidation, and inflammatory markers in RA. The TARA (Trial of Atorvastatin in Rheumatoid Arthritis) study [8] showed that atorvastatin for 6 months had a significant effect on lowering inflammatory markers, and subsequently in a non-RA study, the Justification for the Use of Statins in Prevention: an Intervention Trial Evaluating Rosuvastatin (JUPITER) trial, rosuvastatin treatment in healthy individuals with 
Figure 2. All components of rheumatoid arthritis pathophysiology contribute to the development of cardiovascular disease

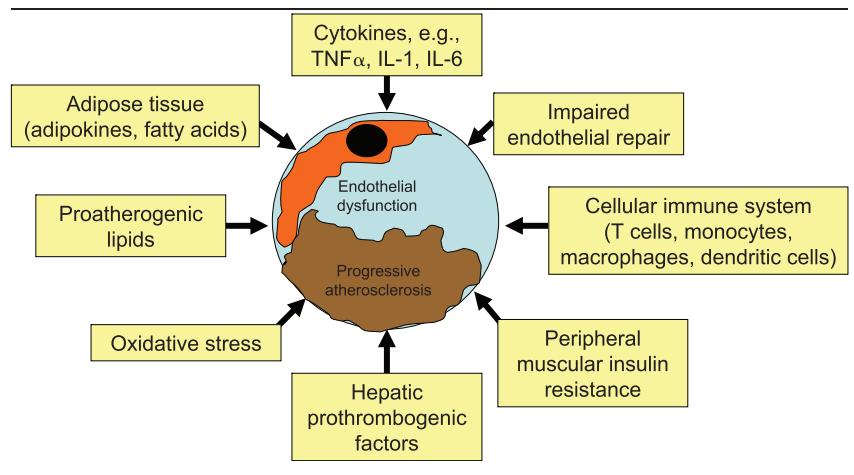

IL, interleukin; TNF $\alpha$, tumor necrosis factor-alpha.

normal low-density lipoprotein (LDL) cholesterol but elevated C-reactive protein (CRP) ( $>2 \mathrm{mg} / \mathrm{L}$ ) was found to reduce cardiac events by nearly half. The authors stated that, although this study excluded patients with chronic inflammatory autoimmune disease, nearly all RA patients would have met the inclusion criteria for JUPITER $[9,10]$.

Similar to the current strategy of treating RA as early as possible in order to avoid structural damage to the affected joints, there are convincing data that antagonizing inflammation early in the course of the disease might be the key to CV protection. It was shown, for example, that inflammation predicts accelerated brachial arterial wall changes in patients with recent-onset RA [11]. Both flow-mediated dilatation and independent glyceryltrinitrate-mediated dilatation were significantly lower at baseline in early-onset RA patients than in controls but could be improved over the course of 1 year with antirheumatic treatment. Of note, the age of the patient, CRP level at initiation of treatment, and CRP level at 1 year were associated with alterations in brachial responses.

\section{Recent advances}

Recommendations of the European Society of Cardiology As CV diseases are among the most frequent diseases affecting overall morbidity and mortality worldwide, a milestone for assessing and improving the overall $\mathrm{CV}$ risk was the work of the task force led by the European Society of Cardiology (ESC) on general prevention and management of CV in 2007. The key points that need to be addressed when managing individuals at risk for $\mathrm{CV}$ are avoidance of tobacco, lowering $\mathrm{BP}$ to below $140 / 90 \mathrm{~mm} \mathrm{Hg}$, lowering serum cholesterol to below $200 \mathrm{mg} / \mathrm{dL}$ ( $5 \mathrm{mmol} / \mathrm{L}$ ) and more specifically LDL cholesterol to below $100 \mathrm{mg} / \mathrm{dL}$ (2.5 mmol/L), weight reduction, a healthy diet, and physical activity for at least 30 minutes per day. However, these recommendations for the assessment and management of CV risk and the respective CV risk score assessment tools such as the Framingham score and the Systematic Coronary Risk Evaluation (SCORE) model presented by the ESC have been developed for the general population and not specifically for patients with arthritides as an additional morbidity factor [12-14]. In addition to the difficulty that many arthritis patients have in achieving the goal of physical activity without adequate treatment, arthritides (with the exception of a single mention of osteoarthritis) are not noted in these recommendations as an individual or aggravating risk factor per se. However, it has been stated that general inflammatory reactions reflected by elevation of CRP need to be taken into account when approaching this medical problem.

\section{EULAR recommendations}

To improve the situation for the practicing rheumatologist, the European League against Rheumatism (EULAR) recently published recommendations for $\mathrm{CV}$ risk management in patients with RA, ankylosing spondylitis (AS), or psoriatic arthritis (PsA) [15]. The working group analyzed all available data and proposed 10 recommendations addressing the $\mathrm{CV}$ risk management in patients with RA, AS, or PsA (Figure 3). Of note, reflecting the clinically overt inflammation in patients with RA, the evidence for an increased CV risk was more prominent for patients with RA and the strength of the recommendations differed also between RA on the one hand and AS and PsA on the other.

In RA patients, the absolute risk of CV-related death is highest for older male patients, whereas the relative risk is highest for young female patients [16]. The EULAR task force stated that the excess $\mathrm{CV}$ risk in RA is due mainly to inflammation rather than the conventional risk factors. In support of this idea, it was found that chronic inflammatory markers such as CRP were independently associated with CV mortality and morbidity. As outlined above, the SMRs range from 1.5 to 1.9 , and similar ratios are suspected for the spondyloarthopathies.

According to the European guidelines of cardiology societies, risk assessment should follow the SCORE model and treatment of the non-arthritic non-inflammatory risk factors should be performed according to these recommendations. Statins, angiotensin-converting enzyme inhibitors, and/or AT-II (angiotensin-II) blockers - owing to their potential anti-inflammatory effects - are preferred treatment options to achieve these goals $[8,9,16-19]$. 
Figure 3. The 10 recommendations for cardiovascular risk management in inflammatory arthritides as outlined by the European League against Rheumatism (EULAR) task force [15]

\begin{tabular}{|c|c|c|}
\hline Recommendations & $\begin{array}{l}\text { Level of } \\
\text { evidence }\end{array}$ & $\begin{array}{l}\text { Strength of } \\
\text { recommendation }\end{array}$ \\
\hline $\begin{array}{l}\text { 1. RA should be regarded as a condition associated with higher risk for CV } \\
\text { disease. This may apply to AS and PsA, although the evidence-base is less. } \\
\text { The increased risk appears to be due to both an increased prevalence of } \\
\text { traditional risk factors and the inflammatory burden. }\end{array}$ & $2 b-3$ & $\mathrm{~B}$ \\
\hline 2. Adequate control of disease activity is necessary to lower the $\mathrm{CV}$ risk. & $2 b-3$ & $\mathrm{~B}$ \\
\hline $\begin{array}{l}\text { 3. CV risk assessment using National Guidelines is recommended for all RA } \\
\text { patients and should be considered for all AS and PsA patients on an annual } \\
\text { basis. Risk assessments should be repeated when anti-rheumatic treatment has } \\
\text { been changed. }\end{array}$ & $3-4$ & $\mathrm{C}$ \\
\hline $\begin{array}{l}\text { 4. Risk score models should be adapted for RA patients by introducing a } 1.5 \\
\text { multiplication factor. This multiplication factor should be used when the RA } \\
\text { patient meets } 2 \text { of the following } 3 \text { criteria: }\end{array}$ & $3-4$ & $\mathrm{C}$ \\
\hline $\begin{array}{l}\text { - Disease duration of more than } 10 \text { years; } \\
\text { - RF or anti-CCP positivity; } \\
\text { - Presence of certain extra-articular manifestations. }\end{array}$ & & \\
\hline 5. TC/HDL cholesterol ratio should be used when the SCORE model is used. & 3 & $\mathrm{C}$ \\
\hline 6. Intervention should be carried out according to national guidelines. & 3 & $\mathrm{C}$ \\
\hline 7. Statins, ACE-inhibitors and/or AT-II blockers are preferred treatment options. & $2 a-3$ & C-D \\
\hline $\begin{array}{l}\text { 8. The role of COXIBs and most NSAIDs regarding the CV risk is not well } \\
\text { established and needs further investigation. Hence, we should be very } \\
\text { cautious prescribing them, especially in patients with a documented CV } \\
\text { disease or in the presence of CV risk factors. }\end{array}$ & $2 a-3$ & $\mathrm{C}$ \\
\hline 9. Corticosteroids: use the lowest dose possible. & 3 & $\mathrm{C}$ \\
\hline 10. Recommend smoking cessation & 3 & $\mathrm{C}$ \\
\hline
\end{tabular}

ACE, angiotensin-converting enzyme; anti-CCP, anti-cyclic citrullinated peptide; AS, ankylosing spondylitis; AT-II, angiotensin-II; COXIB, cyclooxygenase inhibitor; CV, cardiovascular; NSAID, non-steroidal anti-inflammatory drug; PsA, psoriatic arthritis; RA, rheumatoid arthritis; RF, rheumatoid factor; SCORE, Systematic Coronary Risk Evaluation; TC/HDL, total cholesterol/high-density lipoprotein.

Reproduced from Peters et al., 2010 [15] with permission. Copyright (C) 2010 BM] Publishing Group Ltd.

\section{Arthritis-specific laboratory parameters}

As mentioned before, laboratory parameters associated with inflammation or distinct arthritis entities can be used in managing arthritis patients at risk for CV disease. CRP levels, in particular, have been found to be associated with a high CV risk in patients with RA [20]. In addition, the EULAR task force recommended that clinicians multiply the derived CV risk estimate by 1.5 if at least two of the following criteria are present: disease duration of more than 10 years, severe extra-articular manifestations, and, more specifically, rheumatoid factor or anti-cyclic citrullinated peptide antibody positivity (or both) [12].

\section{The basis of anti-inflammatory therapy: corticosteroids and non-steroidal anti-inflammatory drugs}

Corticosteroids are frequently used in rheumatic patients and may enhance the CV morbidity due to their negative effects on metabolism (e.g., lipids, glucose, BP, and obesity). Interestingly, this has been challenged by a 
recent report showing that, although the metabolic syndrome did affect $40 \%$ of the RA patients in the study, long-term corticosteroid treatment did not appear to be associated with a higher prevalence of the metabolic syndrome in patients with RA [21]. In addition, corticosteroids not only contribute to the reduction of overall inflammatory activity but also have proven to be effective in decreasing the risk of atherosclerosis and improving glucose intolerance and dyslipidemia $[22,23]$. However, more data specifically addressing the long-term effect of corticosteroids on alteration of $\mathrm{CV}$ risk are needed.

Of interest, although more than 50,000 patients have been examined for CV risk caused by non-steroidal antiinflammatory drugs (NSAIDs), specifically cyclooxygenase-2 (COX-2) inhibitors (known as 'coxibs'), the EULAR task force concludes that the role of COX-2 inhibitors and most other NSAIDs regarding CV risk is not well established in patients with inflammatory arthritides and needs further investigation. This statement is based on the observations that COX-2 inhibitors can exert prothrombotic effects and that regular use of NSAIDs may impair the vasculoprotective role of acetyl-salicylic acid $[24,25]$. However, a recent analysis did not show a significant difference in CV risk factors between users and non-users of NSAIDs or COX-2 inhibitors, respectively, in a cohort of patients with RA [26].

\section{Novel aspects of disease-modifying antirheumatic drugs and biologics}

Disease-modifying antirheumatic drugs have been shown to improve the lipid profile in patients with early active RA $[23,27]$, and most recently it was demonstrated that methotrexate (MTX) use not only is associated with a lowered occurrence of the metabolic syndrome [28] but also appears to specifically reduce atherosclerosis [29]. As MTX may induce vasculotoxic hyperhomocysteinemia through a depletion of folic acid levels, the current recommendation of folic acid supplementation should also be followed to support the vasculoprotective effects of MTX, although hyperhomocystemia is not the primary reason for folic acid supplementation.

Since the start of the era of tumor necrosis factor (TNF) blockers at the beginning of this millennium, the role of TNF in the development of CV risk in arthritic diseases has been investigated more closely due to its prominent role in inflammation. TNF blockers have been found to be associated with increased high-density lipoproteincholesterol (HDL-c) and improvement of the total cholesterol/HDL-c ratio during the first few months of treatment.
When the body of data addressing the effects of TNF inhibition was reviewed, it was confirmed that TNF blockers actually have vasculoprotective and cardioprotective effects in arthritis patients on the basis of a good level of evidence $[2,12,30,31]$. Of note, an important aspect of the study of Dixon and Symmons [30] is the observation that the decrease in CV events was observed in TNF responders only. A recent analysis of the German cohort showed a reduction of the $\mathrm{CV}$ hazard ratio related to TNF inhibitor treatment to 0.70 , although it needs to be mentioned that this investigation focused on heart failure and not primarily on atherosclerotic disease [31]. However, improvement of $\mathrm{CV}$ risk load can be directly visualized by measurement of the inflammation-associated stiffness, and two current publications demonstrated an improvement of the arterial stiffness for etanercept in RA patients and for infliximab in AS patients $[32,33]$.

\section{Implications for clinical practice}

The current data show impressively that reducing inflammation is one of the most important factors to prevent arthritis patients from developing an additional CV disease. Fortunately, the currently used antiphlogistic and antirheumatic drugs support this goal and low disease activity at the joints results in low atherogenic activity at the vessels, especially when used early in the course of the disease $[19,23,27-30,32,33]$. However, the key problem for the practicing rheumatologist is the lack of time to explain the additional general $\mathrm{CV}$ risk factors and their management in addition to the already time-consuming management of the underlying arthritic disease. Modification of lifestyle, especially cessation of smoking, is one of the most difficult goals to achieve. On the other hand, when improvement of the course of the rheumatic disease is achieved, the overall health of the patient will also improve. Thus, the current evidence for $\mathrm{CV}$ medicine in rheumatology can be summarized as: What is good for the joints is good for the heart and vice versa!

\section{Abbreviations}

AS, ankylosing spondylitis; BP, blood pressure; COX-2, cyclooxygenase-2; CRP, C-reactive protein; CV, cardiovascular; ESC, European Society of Cardiology; EULAR, European League against Rheumatism; HDL-c, highdensity lipoprotein-cholesterol; JUPITER, Justification for the Use of Statins in Prevention: an Intervention Trial Evaluating Rosuvastatin; LDL, low-density lipoprotein; MTX, methotrexate; NSAID, non-steroidal anti-inflammatory drug; PsA, psoriatic arthritis; RA, rheumatoid arthritis; SCORE, Systematic Coronary Risk Evaluation; SMR, standard mortality ratio; TNF, tumor necrosis factor. 


\section{Competing interests}

With respect to the pharmaceutical products mentioned in this report, UM-L and UL have received speaker honoraria from Medac (Wedel, Germany), Essex (München, Germany), and Wyeth (Madison, NJ, USA), and IHT has received speaker honoraria from Abbott (Abbott Park, IL, USA) and Wyeth. CH declares that he has no competing interests.

\section{References}

I. Meune C, Touze E, Trinquart L, Allanore Y: Trends in cardiovascular mortality in patients with rheumatoid arthritis over 50 years: a systematic review and meta-analysis of cohort studies. Rheumatology 2009, 48:1309-13.

2. Bergström U, Jacobsson LT, Turesson C: Cardiovascular morbidity and mortality remain similar in two cohorts of patients with long-standing rheumatoid arthritis seen in 1978 and 1995 in Malmö, Sweden. Rheumatology 2009, 48:1600-5.

3. van Halm VP, Peters MJ, Voskuyl AE, Boers M, Lems WF, Visser M, Stehouwer CD, Spijkerman AM, Dekker JM, Nijpels G, Heine RJ, Bouter LM, Smulders YM, Dijkmans BA, Nurmohamed MT: Rheumatoid arthritis versus diabetes as a risk factor for cardiovascular disease: a cross-sectional study, the CARRE Investigation. Ann Rheum Dis 2009, 68:1395-400.

4. Peters MJ, van Halm VP, Voskuyl AE, Smulders $Y M$, Boers $M$, Lems WF, Visser M, Stehouwer CD, Dekker JM, Nijpels G, Heine R, Dijkmans BA, Nurmohamed MT: Does rheumatoid arthritis equal diabetes mellitus as an independent risk factor for cardiovascular disease? A prospective study. Arthritis Rheum 2009, 6I: I57I-9.

\section{FI000 Factor 3.0 Recommended \\ Evaluated by Francis Guillemin II Jan 2010}

5. Full LE, Ruisanchez C, Monaco C: The inextricable link between atherosclerosis and prototypical inflammatory diseases rheumatoid arthritis and systemic lupus erythematosus. Arthritis Res Ther 2009, I I:217.

6. Ku IA, Imboden JB, Hsue PY, Ganz P: Rheumatoid arthritis - A model of systemic inflammation driving atherosclerosis. Circ J 2009, 73:977-85.

7. Flammer AJ, Sudano I, Hermann F, Gay S, Forster A, Neidhart M, Künzler P, Enseleit F, Périat D, Hermann M, Nussberger J, Luscher TF, Corti R, Noll G, Ruschitzka F: Angiotensin-converting enzyme inhibition improves vascular function in rheumatoid arthritis. Circulation 2008, II 7:2262-9.

8. McCarey DW, Mclnnes IB, Madhok R, Hampson R, Scherbakov O, Ford I, Capell HA, Sattar N: Trial of Atorvastatin in Rheumatoid Arthritis (TARA): double-blind, randomised placebo-controlled trial. Lancet 2004, 363:20I5-2I.

9. Ridker PM, Danielson E, Fonseca FA, Genest J, Gotto AM Jr, Kastelein JJ, Koenig W, Libby P, Lorenzatti AJ, MacFadyen JG, Nordestgaard BG, Shepherd J, Willerson JT, Glynn RJ; JUPITER Study Group: Rosuvastatin to prevent vascular events in men and women with elevated C-reactive protein. N Engl J Med 2008, 359:2195-207.

Changes Clinical Practice

FI000 Factor 10.0 Exceptional

Evaluated by Melvin Cheitlin 28 Nov 2008, Seth Field 09 Feb 2009, Judy Kersten 26 Mar 2009, Conrado Estol 30 Mar 2009, Philipp M Lepper 08 Apr 2009

10. Ward MM: The JUPITER study: statins for the primary prevention of cardiovascular events in patients with inflammatory rheumatic diseases? Fl000 Med Reports 2009, 1:M35.

II. Hannawi S, Marwick TH, Thomas R: Inflammation predicts accelerated brachial arterial wall changes in patients with recent-onset rheumatoid arthritis. Arthritis Res Ther 2009, I I: R5I.
12. Graham I, Atar D, Borch-Johnsen K, Boysen G, Burell G, Cifkova R, Dallongeville J, De Backer G, Ebrahim S, Gjelsvik B, HerrmannLingen C, Hoes A, Humphries S, Knapton M, Perk J, Priori SG, Pyorala K, Reiner Z, Ruilope L, Sans-Menendez S, Op Reimer WS, Weissberg P, Wood D, Yarnell J, Zamorano JL, Walma E, Fitzgerald T, Cooney MT, Dudina A, Vahanian A, et al. : European guidelines on cardiovascular disease prevention in clinical practice: full text. Fourth Joint Task Force of the European Society of Cardiology and other societies on cardiovascular disease prevention in clinical practice (constituted by representatives of nine societies and by invited experts). Eur J Cardiovasc Prev Rehabil 2007, I4(Suppl 2):SI-II3.

13. Conroy RM, Pyörälä K, Fitzgerald AP, Sans S, Menotti A, De Backer G, De Bacquer $D$, Ducimetière $P$, Jousilahti $P$, Keil $U$, Njølstad I, Oganov RG, Thomsen T, Tunstall-Pedoe H, Tverdal A, Wedel H, Whincup P, Wilhelmsen L, Graham IM; SCORE project group: Estimation of ten-year risk of fatal cardiovascular disease in Europe: the SCORE project. Eur Heart J 2003, 24:987-I003.

14. Wilson PW, D'Agostino RB, Levy D, Belanger AM, Silbershatz H, Kannel WB: Prediction of coronary heart disease using risk factor categories. Circulation 1998, 97: 1837-47.

15. Peters MJ, Symmons DP, McCarey D, Dijkmans BA, Nicola P, Kvien TK, Mclnnes IB, Haentzschel H, Gonzalez-Gay MA, Provan S, Semb A, Sidiropoulos P, Kitas G, Smulders YM, Soubrier M, Szekanecz Z, Sattar N, Nurmohamed MT: EULAR evidencebased recommendations for cardiovascular risk management in patients with rheumatoid arthritis and other forms of inflammatory arthritis. Ann Rheum Dis 2010, 69:325-31.

Changes Clinical Practice

FI000 Factor 6.0 Must Read

Evaluated by Zoltán Szekanecz 07 Oct 2009

16. Solomon DH, Goodson NJ, Katz JN, Weinblatt ME, Avorn J, Setoguchi S, Canning C, Schneeweiss S: Patterns of cardiovascular risk in rheumatoid arthritis. Ann Rheum Dis 2006, 65:1608-12.

17. Baigent C, Keech A, Kearney PM, Blackwell L, Buck G, Pollicino C, Kirby A, Sourjina T, Peto R, Collins R, Simes R; Cholesterol Treatment Trialists' (CTT) Collaborators: Efficacy and safety of cholesterol-lowering treatment: prospective meta-analysis of data from 90,056 participants in 14 randomised trials of statins. Lancet 2005, 366:1267-78.

\section{Changes Clinical Practice}

FI000 Factor 6.4 Must Read

Evaluated by Wilbert Aronow 26 Jan 2006, Guy De Backer 02 Feb 2006

18. Okamoto H, Koizumi K, Kamitsuji S, Inoue E, Hara M, Tomatsu T, Kamatani N, Yamanaka $H$ : Beneficial action of statins in patients with rheumatoid arthritis in a large observational cohort. J Rheumatol 2007, 34:964-8.

19. Mäki-Petäjä KM, Booth AD, Hall FC, Wallace SM, Brown J, McEniery CM, Wilkinson IB: Ezetimibe and simvastatin reduce inflammation, disease activity, and aortic stiffness and improve endothelial function in rheumatoid arthritis. J Am Coll Cardiol 2007, 50:852-8.

20. Graf J, Scherzer R, Grunfeld C, Imboden J: Levels of C-reactive protein associated with high and very high cardiovascular risk are prevalent in patients with rheumatoid arthritis. PLOS ONE 2009, 4:e6242.

21. Toms TE, Panoulas VF, Douglas KM, Griffiths HR, Kitas GD: Lack of association between glucocorticoid use and presence of the metabolic syndrome in patients with rheumatoid arthritis: a cross-sectional study. Arthritis Res Ther 2008, I0:RI45.

22. Hallgren $R$, Berne $C$ : Glucose intolerance in patients with chronic inflammatory diseases is normalized by glucocorticoids. Acta Med Scand 1983, 213:35I-5.

23. Boers M, Nurmohamed MT, Doelman CJ, Lard LR, Verhoeven AC Voskuyl AE, Huizinga TW, van de Stadt RJ, Dijkmans BA, van der Linden S: Influence of glucocorticoids and disease activity on total and high density lipoprotein cholesterol in patients with rheumatoid arthritis. Ann Rheum Dis 2003, 62:842-5. 
24. Crofford LJ, Breyer MD, Strand CV, Rushitzka F, Brune K, Farkouh ME, Simon LS: Cardiovascular effects of selective COX-2 inhibition: is there a class effect? The International COX-2 Study Group. J Rheumatol 2006, 33:1403-8.

25. Hudson M, Baron M, Rahme E, Pilote L: Ibuprofen may abrogate the benefits of aspirin when used for secondary prevention of myocardial infarction. J Rheumatol 2005, 32:1589-93.

26. Rho YH, Oeser A, Chung CP, Milne GL, Stein M: Drugs used in the treatment of rheumatoid arthritis: relationship between current use and cardiovascular risk factors. Arch Drug Inf 2009, 2:34-40.

27. Park YB, Choi HK, Kim MY, Lee WK, Song J, Kim DK, Lee SK: Effects of antirheumatic therapy on serum lipid levels in patients with rheumatoid arthritis: a prospective study. Am J Med 2002, II3:188-93.

28. Toms TE, Panoulas VF, John H, Douglas KM, Kitas GD: Methotrexate therapy associates with reduced prevalence of the metabolic syndrome in rheumatoid arthritis patients over the age of 60- more than just an anti-inflammatory effect? A cross sectional study. Arthritis Res Ther 2009, II:RIIO.
29. Westlake SL, Colebatch AN, Baird J, Kiely P, Quinn M, Choy E, Ostor AJ, Edwards CJ: The effect of methotrexate on cardiovascular disease in patients with rheumatoid arthritis: a systematic literature review. Rheumatology 2010, 49:295-307.

30. Dixon WG, Symmons DP: What effects might anti-TNFa treatment be expected to have on cardiovascular morbidity and mortality in rheumatoid arthritis? A review of the role of TNFo in cardiovascular pathophysiology. Ann Rheum Dis 2007, 66: 1132-6.

31. Listing J, Strangfeld A, Kekow J, Schneider M, Kapelle A, Wassenberg S, Zink A: Does tumor necrosis factor alpha inhibition promote or prevent heart failure in patients with rheumatoid arthritis? Arthritis Rheum 2008, 58:667-77.

32. Galarraga B, Khan F, Kumar P, Pullar T, Belch J]: Etanercept improves inflammation-associated arterial stiffness in rheumatoid arthritis. Rheumatology 2009, 48: |4|8-23.

33. van Eijk IC, Peters MJ, Serné EH, van der Horst-Bruinsma IE, Dijkmans BA, Smulders YM, Nurmohamed MT: Microvascular function is impaired in ankylosing spondylitis and improves after tumour necrosis factor- $\alpha$ blockade. Ann Rheum Dis 2009, 68:362-6. 